\title{
Physiological changes during low- and high-intensity noninvasive ventilation
}

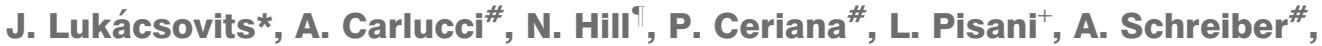 \\ P. Pierucci ${ }^{\#}$, G. Losonczy* and S. Nava ${ }^{\S}$
}

ABSTRACT: In a physiological randomised cross-over study performed in stable hypercapnic chronic obstructive disease patients, we assessed the short-term effects of two settings of noninvasive ventilation.

One setting was aimed at maximally reducing arterial carbon dioxide tension $\left(\mathrm{Pa}, \mathrm{CO}_{2}\right)(\mathrm{high}$ intensity ( $\mathrm{Hi})$ noninvasive positive pressure ventilation (NPPV)): mean $\pm \mathrm{SD} 27.6 \pm 2.1 \mathrm{cmH}_{2} \mathrm{O}$ of inspiratory positive airway pressure, $4 \pm 0 \mathrm{cmH}_{2} \mathrm{O}$ of expiratory positive airway pressure and respiratory rate of 22 breaths $\mathrm{min}^{-1}$. The other was performed according to the usual parameters used in earlier studies (low-intensity (Li)-NPPV): $17.7 \pm 1.6 \mathrm{cmH}_{2} \mathrm{O}$ of inspiratory positive airway pressure, $4 \pm 0 \mathrm{cmH}_{2} \mathrm{O}$ of expiratory positive airway pressure and respiratory rate of 12 breaths $\cdot \mathrm{min}^{-1}$.

Both modes of ventilation significantly improved gas exchange compared with spontaneous breathing (SB), but to a greater extent using $\mathrm{Hi}-\mathrm{NPPV}\left(\mathrm{Pa}_{1} \mathrm{CO}_{2} \quad 59.3 \pm 7.5,55.2 \pm 6.9\right.$ and 49.4 $\pm 7.8 \mathrm{mmHg}$ for SB, Li-NPPV and Hi-NPPV, respectively). Similarly, Hi-NPPV induced a greater reduction in the pressure-time product of the diaphragm per minute from $323 \pm 149 \mathrm{cmH}_{2} \mathrm{O} \cdot \mathrm{s} \cdot \mathrm{min}^{-1}$ during SB to $132 \pm 139 \mathrm{cmH}_{2} \mathrm{O} \cdot \mathrm{s} \cdot \mathrm{min}^{-1}$ during Li-NPPV and $40 \pm 69 \mathrm{cmH}_{2} \mathrm{O} \cdot \mathrm{s} \cdot \mathrm{min}^{-1}$ during Hi-NPPV, while in nine out of 15 patients, it completely abolished SB activity. Hi-NPPV also induced a marked reduction in cardiac output $(\mathrm{CO})$ measured noninvasively with a Finometer PRO (Finapres Medical Systems BV, Amsterdam, the Netherlands) compared with Li-NPPV.

We conclude that while Hi-NPPV is more effective than Li-NPPV in improving gas exchange and in reducing inspiratory effort, it induces a marked reduction in $\mathrm{CO}$, which needs to be considered when Hi-NPPV is applied to patients with pre-existing cardiac disease.

KEYWORDS: Chronic obstructive pulmonary disease, noninvasive ventilation, respiratory mechanics

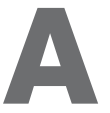
recent systematic review on the use of long-term noninvasive ventilation (NIV) in stable hypercapnic chronic obstructive pulmonary disease (COPD) patients was inconclusive as, despite improvement in lung hyperinflation, gas exchange and diaphragmatic effort, no major long-term clinical advantages were observed in randomised controlled trials [1, 2].

Inconsistency in the effectiveness of NIV on the assessed outcomes may be due, among other variables, to the levels of the applied inspiratory and expiratory pressure [3]. It has been suggested that the "appropriate" NIV setting to reduce the work of breathing by at least $40 \%$ including the portion due to the presence of intrinsic positive end-expiratory pressure (PEEPi) [4] is achieved clinically on the basis of the patient's tolerance and improvement in arterial blood gases. The mean inspiratory pressure applied in that physiological study [3] was $\sim 15 \mathrm{cmH}_{2} \mathrm{O}$, which is very close to the average values employed in most of the randomised long-term trials [3, 4].

Higher inspiratory pressures $\left(28 \mathrm{cmH}_{2} \mathrm{O}\right)$ and respiratory rates $\left(20\right.$ breaths $\cdot \mathrm{min}^{-1}$ ) were recently adopted to ventilate chronic hypercapnic COPD patients in order to achieve maximal arterial carbon dioxide tension $\left(\mathrm{Pa}, \mathrm{CO}_{2}\right)$ reduction. This type of approach, called high-intensity (Hi) noninvasive positive pressure ventilation (NPPV), has been shown to improve spontaneous diurnal blood gases more than the traditional lower pressures approach (low-intensity (Li)-NPPV). A long-term randomised study will be necessary to determine the effect of Hi-NPPV on long-term survival [5-7].

No data are available, however, to assess physiological effects of this atypical setting on diaphragmatic activity and worsening of dynamic

\section{AFFILIATIONS}

${ }^{*}$ Dept of Pulmonology, Semmelweis University, Budapest, Hungary. ${ }^{\text {\#} F o n d a z i o n e ~ S a l v a t o r e ~ M a u g e r i ~}$ Pavia, Istituto Scientifico di Pavia, IRCCS, Pavia,

+University la Sapienza, Rome, and ${ }^{\S}$ Respiratory Intensive Care Unit, Azienda Opedaliera Universitaria Sant' Orsola-Malpighi, Bologna, Italy. 'Tufts Medical Center, Boston, MA, USA.

CORRESPONDENCE S. Nava

Azienda Opedaliera Universitaria Sant' Orsola-Malpighi Via Massarenti 9 40138 Bologna Italy E-mail: stefano.nava@aosp.bo.it

Received:

March 312011 Accepted after revision: Aug 052011

First published online: Sept 012011 
hyperinflation or auto-PEEP. Moreover, through an increase in intrathoracic pressure, Hi-NPPV could reduce cardiac output (CO) $[8,9]$.

In this randomised cross-over study, we investigated the acute physiological changes of Hi-NPPV versus Li-NPPV in order to clarify the possible detrimental effects of this new ventilatory strategy.

\section{MATERIALS AND METHODS}

We studied 15 patients who were admitted to the Dept of Respiratory Rehabilitation, Fondazione Salvatore Maugeri, Pavia, Italy for management of chronic hypercapnic respiratory failure due to COPD. At the time of the study, all patients were in a phase of clinical and haemodynamic stability. The patients' characteristics, including pulmonary function tests and arterial blood gases at the time of the study, are shown in table 1. Enrolment criteria were the presence of chronic hypercapnic respiratory failure (i.e. $\mathrm{pH} \geqslant 7.35$ and $\mathrm{Pa}_{1} \mathrm{CO}_{2}$ $\geqslant 50 \mathrm{mmHg}$ ), while exclusion criteria were the presence of cancer, neuromuscular disease or an ejection fraction (EF) recorded during an echocardiography study of $<40 \%$ (the mean \pm SD in enrolled patients was $58.9 \pm 11 \%$ ). The study was approved by the local ethics committee and written informed consent was obtained from all patients.

\section{Protocol}

The ventilator therapy was stopped at least $1 \mathrm{~h}$ before the beginning of each trial. The patients were studied in a semirecumbent position while inspiring additional oxygen. At the beginning of the trial, the patients were asked to breath for a few minutes without any ventilatory assistance (baseline recordings). The physiological data were recorded during two randomised trials, each with different ventilatory settings over $30 \mathrm{~min}$, separated by a return to spontaneous breathing (SB) for $10 \mathrm{~min}$. The randomisation of the trials was obtained using an ad hoc computer program in order to evenly distribute the sequence. The patients were ventilated with a respirator with a dedicated NIV platform (HARMONY (Philips, Amsterdam, the Netherlands), Vivo 50 (Breas, Mölnlycke, Sweden) and V60 (Philips)) and with a full-face mask tailored to each patient's facial features. Great care was taken by the respiratory therapists in charge of NIV, who were blinded to the protocol, to avoid any possible air leaks. Adjustment of the mask was checked at the beginning of each trial. The inspired fraction of oxygen during the different ventilatory settings was estimated according to THYs et al. [10].

\section{Li-NPPV}

All the patients had stable hypercapnic COPD and were admitted to our unit for a possible home ventilation programme. They were, therefore, familiarised with NIV in the preceding few days, using our usual clinical protocol [3] aimed at reducing $\mathrm{Pa}_{\mathrm{a}}, \mathrm{CO}_{2}$ by $>10 \%$ while on ventilation $\left(\mathrm{Pa}, \mathrm{CO}_{2}\right.$ at hospital admission during SB $62.3 \pm 8.2 \mathrm{mmHg}$ and $56.3 \pm 7.5 \mathrm{mmHg}$ during the NIV adaptation trial), achieving an expired tidal volume $(V \mathrm{~T})$ of $6-8 \mathrm{~mL} \cdot \mathrm{kg}^{-1}$ and a reduction of transdiaphragmatic pressure $(P \mathrm{di})$ to $50 \%$ of baseline during the measurement of respiratory mechanics. These settings were chosen by the attending clinician, who was unaware of the aim of the study. The mean \pm SD inspiratory support was $17.7 \pm 1.6 \mathrm{cmH}_{2} \mathrm{O}$ (range $15-20 \mathrm{cmH}_{2} \mathrm{O}$ ) with an external continuous positive airway pressure of $4 \mathrm{cmH}_{2} \mathrm{O}$ and a backup rate of 12 breaths $\cdot \mathrm{min}^{-1}$.

\section{Hi-NPPV}

With Hi-NPPV, we aimed to reach the maximum tolerated inspiratory pressure (at least 50\% greater than Li-NPPV) by increasing pressures stepwise by $0.5 \mathrm{cmH}_{2} \mathrm{O}$. This allowed us

\section{TABLE 1 Patients' characteristics including pulmonary function tests and arterial blood gases}

\begin{tabular}{|c|c|c|c|c|c|c|c|c|c|}
\hline Patient & Age yrs & Sex & BMI $\mathrm{kg} \cdot \mathrm{m}^{-2}$ & pH & $\mathrm{PCO}_{2} \mathrm{mmHg}$ & $\mathrm{PO}_{2} \mathrm{mmHg}$ & FEV1 L (\% pred) & FVC L (\% pred) & $\mathrm{FEV}_{1 / \text { FVC } \%}$ \\
\hline 1 & 80 & M & 20.6 & 7.45 & 50.10 & 69.80 & 0.52 (23) & 1.07 (35) & 49 \\
\hline 2 & 76 & M & 21.8 & 7.35 & 69.80 & 58.90 & $0.43(20)$ & $1.99(70)$ & 22 \\
\hline 3 & 54 & M & 23.7 & 7.41 & 51.00 & 61.00 & NA & NA & NA \\
\hline 4 & 66 & M & 22.1 & 7.36 & 57.30 & 62.40 & $0.64(22)$ & $2.84(76)$ & 23 \\
\hline 5 & 77 & M & 33.7 & 7.39 & 50.40 & 59.20 & $0.89(46)$ & $1.65(64)$ & 54 \\
\hline 6 & 64 & M & 16.6 & 7.36 & 56.80 & 68.80 & $0.47(20)$ & $2.34(80)$ & 20 \\
\hline 7 & 78 & M & 22.0 & 7.37 & 56.50 & 80.60 & 0.51 (22) & $1.52(48)$ & 34 \\
\hline 8 & 71 & M & 25.8 & 7.41 & 57.90 & 58.70 & $0.52(20)$ & $1.85(54)$ & 28 \\
\hline 9 & 60 & M & 29.4 & 7.35 & 59.10 & 74.70 & 0.59 (18) & 2.18 (53) & 59 \\
\hline 10 & 71 & $\mathrm{~F}$ & 33.2 & 7.36 & 65.00 & 63.80 & NA & NA & NA \\
\hline 11 & 69 & M & 30.2 & 7.35 & 62.80 & 67.50 & $0.48(15)$ & $1.96(46)$ & 24 \\
\hline 12 & 81 & M & 24.5 & 7.41 & 54.20 & 71.90 & $0.63(29)$ & $1.17(40)$ & 54 \\
\hline 13 & 76 & M & 24.5 & 7.35 & 77.30 & 67.10 & 0.65 (23) & $1.47(39)$ & 44 \\
\hline 14 & 76 & M & 13.1 & 7.43 & 64.30 & 79.00 & $0.49(17)$ & $1.7(45)$ & 29 \\
\hline 15 & 78 & M & 26.1 & 7.35 & 56.90 & 73.00 & $0.89(32)$ & $1.83(49)$ & 49 \\
\hline Mean \pm SD & $71.8 \pm 7.8$ & & $24.5 \pm 5.7$ & $7.38 \pm 0.03$ & $59.3 \pm 7.5$ & $67.8 \pm 7.1$ & $\begin{array}{l}0.61 \pm 0.15 \\
(23.6 \pm 8.11)\end{array}$ & $1.68 \pm 0.56(53.8 \pm 14.5)$ & $44.7 \pm 23.13$ \\
\hline
\end{tabular}

BMI: body mass index; $\mathrm{PCO}_{2}$ : carbon dioxide tension; $\mathrm{PO}_{2}$ : oxygen tension; FEV1: forced expiratory volume in 1 s; \% pred: \% predicted; FVC: forced vital capacity; M: male; F: female; NA: not available. 
to reach mean inspiratory pressure values very close to those of WINDISCH and co-workers [5, 6] $\left(27.6 \pm 2.1 \mathrm{cmH}_{2} \mathrm{O}\right.$ used in our study versus $\sim 28 \mathrm{cmH}_{2} \mathrm{O}$ used in previous studies), aiming to maximally decrease $P a, C_{2}$ by stepwise increases in inspiratory pressure [5-7]. As with Li-NPPV, the external PEEP level was fixed at $4 \mathrm{cmH}_{2} \mathrm{O}$ and respiratory rate was set to match the SB rate, usually $20-22$ breaths $\cdot \mathrm{min}^{-1}$.

\section{Measurements}

Arterial blood gases were obtained from a radial artery during $\mathrm{SB}$ and at the end of each ventilatory trial. Flow at the airway opening was measured with a heated pneumotachograph (Model 3700; Hans Rudolph, Shawnee, KS, USA) and a differential pressure transducer $\left( \pm 300 \mathrm{cmH}_{2} \mathrm{O}\right.$; Honeywell, Freeport, IL, USA) placed between the mask and the Y-piece of the ventilator. $V \mathrm{~T}$ was obtained by integration of the flow. Breathing pattern was measured from the flow signal. Expired $V \mathrm{~T}$ was used for data analysis. We also measured the difference between expired and inspired $V \mathrm{~T}$ to quantify the amount of air leakage.

Airway pressure $\left( \pm 300 \mathrm{cmH}_{2} \mathrm{O}\right.$; Honeywell $)$ was measured from a side port between the pneumotachograph and the face mask.

Oesophageal and gastric pressures $\left( \pm 300 \mathrm{cmH}_{2} \mathrm{O}\right.$; Honeywell $)$ were measured with an oesophageal balloon positioned at the lower third of the oesophagus, filled with $0.5 \mathrm{~mL}$ air and a gastric balloon filled with $1 \mathrm{~mL}$ air. The proper position of the balloon was verified using the occlusion test. Pdi was calculated as the difference between gastric and oesophageal pressure.

Pressure-time integrals of the diaphragm (PTPdi) were calculated per breath (pressure-time product of the diaphragm per breath (PTPdi/breath)) and per minute (pressure-time product of the diaphragm per minute (PTPdi/min)). Dynamic PEEPi (PEEPi,dyn) was obtained from the Pdi signal, as the value of $P$ di at the moment of zero flow [11, 12]. Ineffective efforts (IEs) were analysed from the $P$ di traces and expressed as percentage of total breaths measured.

We also measured cardiovascular parameters using a noninvasive device (Finometer PRO; Finapres Medical Systems BV, Amsterdam, the Netherlands) [13]. In this group of patients with normal cardiac performance, this method has a good reliability, with $15 \%$ error relative to invasively obtained values [14] and only $8 \%$ error relative to changes [15] in CO measured by thermodilution.

The Finometer PRO finger cuff was placed on the middle finger and the arm cuff was placed on the same-side upper arm of the patient. The measured and calculated cardiovascular parameters were systolic arterial pressure (SAP), diastolic arterial pressure, mean arterial pressure (MAP), heart rate, stroke volume (SV) and CO.

Dyspnoea was assessed using the Borg scale, with a range of 0 10, at baseline and during the two ventilator trials. For each condition tested, patients placed a finger on the number that best represented the question "how does your breathing feel during this trial of ventilation?" Data obtained in the final 3 min of recording were considered for analysis.

\section{Statistical analysis}

All signals were collected using a personal computer equipped with an analogue/digital board and stored at a sampling rate of $100 \mathrm{~Hz}$. Data are presented as mean \pm SD. Comparisons for each sequence and each continuous variable were performed using ANOVA for repeated measures with the Newman-Keuls post hoc test. The protection test for carry-over effects was also performed [16, 17]. Outcome measures were tested for normality with the Kolmogorov-Smirnov test, and when normality was not achieved, we used the Friedman test. Statistical analysis was performed with Prism (GraphPad, La Jolla, CA, USA) and Medcalc (Medcalc Software, Mariakerke, Belgium). All tests were two-sided. A p-value $<0.05$ was considered statistically significant.

\section{RESULTS}

All patients tolerated the experimental procedures well and completed the study. Eight out of 15 patients were randomised to receive Li-NPPV as the first intervention.

\section{Breathing pattern}

As shown in table 2, compared with baseline conditions, both Hi-NPPV and Li-NPPV significantly increased expired $V \mathrm{~T}$ and minute ventilation $\left(V^{\prime} \mathrm{E}\right)$, but these changes were statistically higher with Hi-NPPV. The amount of air-leaks was significantly lower with Li-NPPV. The mean inspiratory flow was also higher with Hi-NPPV and the duty cycle lower, whereas no statistical difference was observed in breathing frequency.

\section{Respiratory mechanics}

Mean values of respiratory mechanics are presented in table 3. Tidal Pdi, PTPdi/breath and PTPdi/min were significantly reduced compared with $\mathrm{SB}$, but the decrease in all these parameters was significantly greater using Hi-NPPV versus LiNPPV. Indeed, in nine out of 15 patients, the $P$ di trace was flat and the pleural pressure $(P \mathrm{pl})$ even became positive during $\mathrm{Hi}$ NPPV, suggesting a "true" controlled ventilation (fig. 1). For this reason, data on PEEPi,dyn are not presented. Only two out of the six patients with a measurable $P$ di had IEs, both during Li-NPPV $(8.0 \pm 5.5 \%$ of the total breaths) and Hi-NPPV $(1.2 \pm 2.8 \%)$. Lung resistance was also significantly decreased during mechanical ventilation, but no difference was found between the two ventilator settings.

\section{Arterial blood gases}

The mean values of blood gas parameters are presented in table 4. Despite different ventilatory settings, $\mathrm{pH}$ and $\mathrm{Pa}, \mathrm{CO}_{2}$ improved significantly versus baseline conditions, the changes being significantly less pronounced using Li-NPPV than HiNPPV.

\section{Dyspnoea score}

No statistical differences were observed between the two modes of ventilation, but both resulted in a statistical reduction versus baseline (Borg score $6.93 \pm 1.1$ in SB versus $3.13 \pm 1.64$ in Li-NPPV $(p<0.001)$ and $4.67 \pm 1.04$ in Hi-NPPV $(p<0.01))$.

\section{Cardiovascular parameters and oxygen transport}

The mean values of the main cardiovascular parameters and oxygen transport are presented in table 5. Mechanical ventilation induced a significant decrease in SAP, but without any 
TABLE 2 Breathing pattern

\begin{tabular}{|c|c|c|c|c|c|c|}
\hline Parameter & SB & Li-NPPV & Hi-NPPV & SB versus $\mathrm{Li}-\mathrm{NPPV}$ & SB versus $\mathrm{Hi}-\mathrm{NPPV}$ & Li-NPPV versus Hi-NPPV \\
\hline$f R$ breaths $\cdot \mathrm{min}^{-1}$ & $24.8 \pm 8.4$ & $21.3 \pm 6.3$ & $22.9 \pm 3.3$ & NS & NS & NS \\
\hline$t \mid s$ & $1.25 \pm 0.3$ & $1.1 \pm 0.19$ & $0.74 \pm 0.1$ & NS & $<0.05$ & $<0.001$ \\
\hline$t E S$ & $1.46 \pm 0.75$ & $1.98 \pm 0.77$ & $1.93 \pm 0.34$ & NS & NS & NS \\
\hline$V T / t ı L \cdot s^{-1}$ & $0.33 \pm 0.08$ & $0.52 \pm 0.11$ & $0.93 \pm 0.18$ & $<0.05$ & $<0.001$ & $<0.05$ \\
\hline$V^{\prime} E L \cdot \min ^{-1}$ & $9.6 \pm 3.5$ & $11.7 \pm 2.3$ & $15.2 \pm 2.0$ & $<0.01$ & $<0.001$ & $<0.001$ \\
\hline Air leakage $L \cdot \mathrm{min}^{-1}$ & & $10.62 \pm 5.27$ & $16.11 \pm 7.88$ & & & $<0.05$ \\
\hline
\end{tabular}

Data are presented as mean $\pm \mathrm{SD}$, unless otherwise stated. SB: spontaneous breathing; Li: low-intensity; NPPV: noninvasive positive pressure ventilation; Hi: highintensity; fR: respiratory frequency; $t \mathrm{l}$ : inspiratory time; $t \mathrm{E}$ : expiratory time; ttot: total time of respiratory cycle; $V_{\mathrm{T}}$ : tidal volume; $V^{\prime} \mathrm{E}$ : minute ventilation; NS: nonsignificant.

difference between Hi-NPPV and Li-NPPV. NPPV also reduced SV, CO and cardiac index; the decrease was statistically more pronounced with Hi-NPPV than Li-NPPV. Similar changes were observed in the calculated oxygen delivery capacity and the oxygen delivery corrected by body surface area. A statistically significant correlation was observed between the per cent changes from baseline $\mathrm{CO}$ and absolute changes from baseline $P \mathrm{pl}$ in the Hi-NPPV trial $(\mathrm{r}=-0.68, \mathrm{p}<0.01)$. We found similar correlations between changes from baseline airway pressure and per cent changes from baseline CO during Hi-NPPV $(r=-0.59, p<0.05)$.

There were no relationships between baseline left ventricular EFs and the per cent changes from baseline of $\mathrm{CO}$.

\section{DISCUSSION}

The use of NIV in the treatment of chronic respiratory failure due to COPD has had mixed success [2] and for this reason, some researchers have hypothesised that ventilator pressures have been too low and developed a ventilatory technique called Hi-NPPV aimed to maximally reduce $\mathrm{Pa}_{2}, \mathrm{CO}_{2}$ and improve clinical outcomes [5-7]. Previous studies suggest that this approach may not only improve gas exchange but also other clinical parameters, including dyspnoea during physical activity, lung function and health-related quality of life [5, 7].

In the present study, we have assessed the acute physiological changes induced by Hi-NPPV and demonstrate that this novel approach is able to significantly improve $P \mathrm{a}_{1} \mathrm{CO}_{2}$ compared with Li-NPPV, which is most probably related to a greater increase in expired $V$ T and $V^{\prime}$ E. Hi-NPPV is also associated with a marked reduction in PTPdi, an index of diaphragm oxygen expenditure, and in $\mathrm{CO}$ and SV, which could limit the application of Hi-NPPV in patients with pre-existing cardiac disease.

Before proceeding any further, we need to briefly discuss the main aim of Hi-NPPV, which is to maximally reduce the $\mathrm{Pa}_{\mathrm{a}} \mathrm{CO}_{2}$ level. Presently, it is unclear whether hypercapnia per se influences the survival of these patients $[5,18,19]$. Moreover, potential adverse consequences of Hi-NPPV include diaphragm atrophy due to complete rest [20], as suggested by the near abolition of the $P$ di signal seen in most patients; the risk of this seems minimal, however, considering that the respiratory muscles of patients with severe COPD seem to be resistant to fatigue compared with normal subjects [21] and patients using Hi-NPPV are still breathing spontaneously most

\section{TABLE 3 Respiratory mechanics}

\begin{tabular}{|c|c|c|c|c|c|c|}
\hline \multirow[t]{2}{*}{ Parameter } & \multirow[t]{2}{*}{ SB } & \multirow[t]{2}{*}{ Li-NPPV } & \multirow[t]{2}{*}{ Hi-NPPV } & \multicolumn{3}{|c|}{ p-value } \\
\hline & & & & SB versus Li-NPPV & SB versus Hi-NPPV & Li-NPPV versus Hi-NPPV \\
\hline $\mathrm{Pdi}_{\mathrm{din}} \mathrm{cm}_{2} \mathrm{O}$ & $17.9 \pm 8.1$ & $9.09 \pm 2.4$ & $2.83 \pm 4.6$ & $<0.001$ & $<0.001$ & $<0.01$ \\
\hline PTPdi $\mathrm{cmH}_{2} \mathrm{O} \cdot \mathrm{s}$ & $14.9 \pm 7.5$ & $6.3 \pm 5.9$ & $1.6 \pm 2.6$ & $<0.001$ & $<0.001$ & $<0.01$ \\
\hline PTPdi/min $\mathrm{cmH}_{2} \mathrm{O} \cdot \mathbf{s} \cdot \mathrm{min}^{-1}$ & $323 \pm 149$ & $132 \pm 139$ & $40 \pm 69$ & $<0.001$ & $<0.001$ & $<0.01$ \\
\hline$R \mathrm{~L} \mathrm{cmH}_{2} \mathrm{O} \cdot \mathrm{s} \cdot \mathrm{L}^{-1}$ & $22.3 \pm 14.6$ & $11.0 \pm 8.4$ & $11.9 \pm 9.7$ & $<0.01$ & $<0.05$ & NS \\
\hline
\end{tabular}

Data are presented as mean \pm SD, unless otherwise stated. SB: spontaneous breathing; Li: low-intensity; NPPV: noninvasive positive pressure ventilation; Hi: highintensity; Ppl: pleural pressure; Pdi: transdiaphragmatic pressure; PTPdi: pressure-time product of the diaphragm; PTPdi/min: PTPdi per minute; CL,dyn: dynamic lung compliance; RL: pulmonary resistance; NS: nonsignificant. 
SB

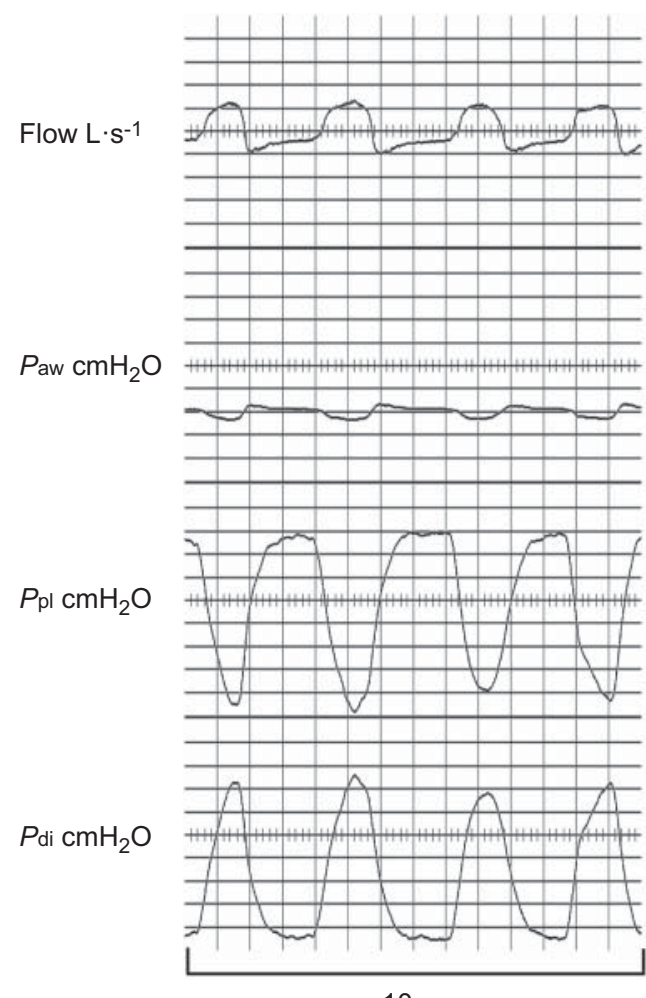

$10 \mathrm{~s}$
Li-NPPV

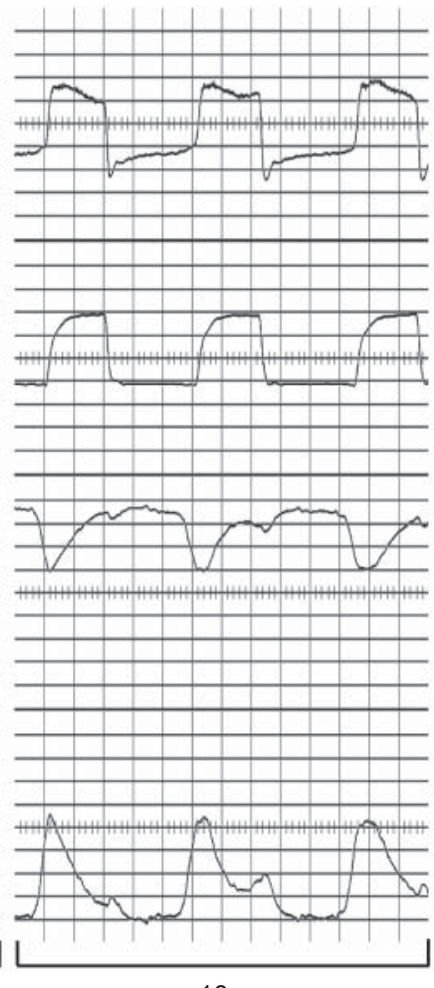

$10 \mathrm{~s}$
Hi-NPPV

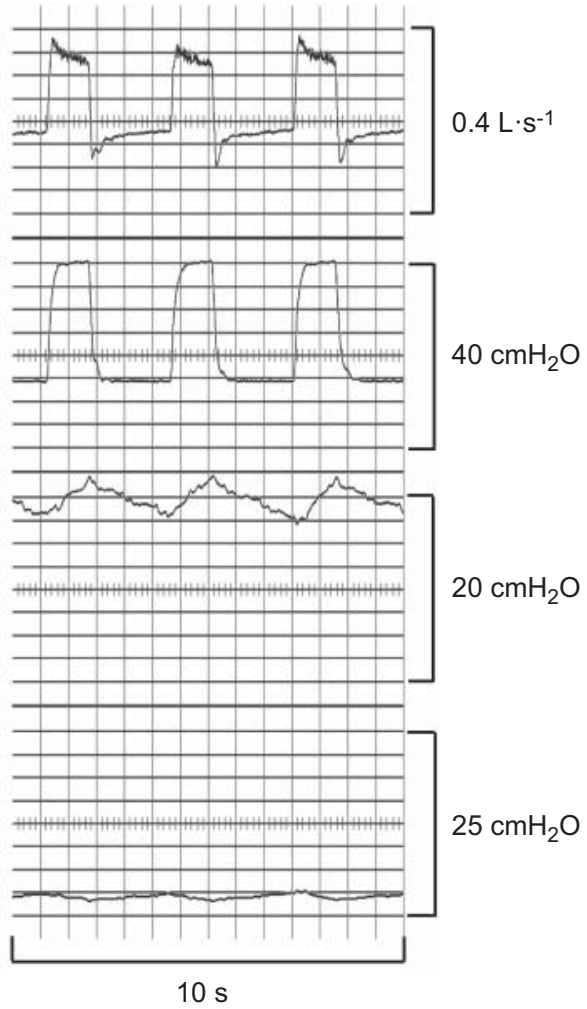

FIGURE 1. Respiratory mechanical parameters during spontaneous breathing (SB), low-intensity (Li) noninvasive positive pressure ventilation (NPPV) and high-intensity (Hi)-NPPV in a characteristic subject. Paw: airway pressure; Ppl: pleural pressure; Pdi: transdiaphragmatic pressure.

of the time, which should minimise atrophy [22]. Another possible detrimental consequence of Hi-NPPV is worsening of pulmonary hyperinflation. Because of the near total abolition of inspiratory muscle activity by Hi-NPPV, we could not calculate PEEPi,dyn using oesophageal tracings. However, the high $V \mathrm{~T}$ in the Hi-NPPV group combined with the increased expiratory time constant of COPD patients probably contributed to greater dynamic hyperinflation than with $\mathrm{SB}$ or LiNPPV. Not only does this increase the risk of barotrauma, but it might also have adverse cardiovascular consequences, as will be discussed further herein.
The development of hypercapnic respiratory failure in COPD patients is mainly related to the occurrence of alveolar hypoventilation caused by a marked increase in the ratio of dead space volume $(V \mathrm{D})$ to $V \mathrm{~T}$. This is a consequence of the reduced $V_{\mathrm{T}}$ that occurs as the failing patient develops a rapid shallow breathing pattern and increased $V D$ that results from a severe ventilation/perfusion $\left(V^{\prime} / Q^{\prime}\right)$ inhomogeneity [23]. NPPV helps to reverse this process by augmenting $V \mathrm{~T}$ and, potentially, reducing $V^{\prime} / Q^{\prime}$ mismatch via application of positive airway pressure. In an animal study, NEUMANN and HEDENSTIERNA [24] found improvement of $V^{\prime} / Q^{\prime}$ inhomogeneity during CPAP

\section{TABLE 4 Blood gas parameters}

\begin{tabular}{|c|c|c|c|c|c|c|}
\hline Parameter & SB & Li-NPPV & Hi-NPPV & SB versus Li-NPPV & SB versus Hi-NPPV & Li-NPPV versus Hi-NPPV \\
\hline $\mathrm{pH}$ & $7.38 \pm 0.03$ & $7.4 \pm 0.03$ & $7.42 \pm 0.03$ & $<0.05$ & $<0.001$ & $<0.01$ \\
\hline $\mathrm{Pa}, \mathrm{CO}_{2} \mathrm{mmHg}$ & $59.3 \pm 7.5$ & $55.2 \pm 6.9$ & $49.4 \pm 7.8$ & $<0.001$ & $<0.001$ & $<0.01$ \\
\hline${\mathrm{Pa}, \mathrm{O}_{2}}_{\mathrm{mmHg}}$ & $67.8 \pm 7.1$ & $65.8 \pm 11.9$ & $71.6 \pm 19.1$ & NS & NS & NS \\
\hline $\mathrm{Fl}, \mathrm{O}_{2} \%$ & $24.2 \pm 2.5$ & $24.3 \pm 2.6$ & $24.3 \pm 2.7$ & NS & NS & NS \\
\hline
\end{tabular}

Data are presented as mean $\pm \mathrm{SD}$, unless otherwise stated. SB: spontaneous breathing; Li: low-intensity; NPPV: noninvasive positive pressure ventilation; Hi: highintensity; $\mathrm{Pa}_{1} \mathrm{CO}_{2}$ : arterial carbon dioxide tension; $\mathrm{Pa}_{\mathrm{a}} \mathrm{O}_{2}$ : arterial oxygen tension; $\mathrm{BE}$ : base excess; $\mathrm{Fl}, \mathrm{O}_{2}$ : inspiratory oxygen fraction; NS: nonsignificant. 
TABLE 5 Mean values of main cardiovascular parameters and oxygen transport

\begin{tabular}{|c|c|c|c|c|c|c|}
\hline Parameter & SB & Li-NPPV & Hi-NPPV & SB versus Li-NPPV & SB versus Hi-NPPV & Li-NPPV versus Hi-NPPV \\
\hline SAP $\mathrm{mmHg}$ & $126 \pm 22$ & $118 \pm 20$ & $112 \pm 21$ & $<0.05$ & $<0.01$ & NS \\
\hline DAP $\mathrm{mmHg}$ & $71 \pm 7.7$ & $69 \pm 7.8$ & $70 \pm 8.2$ & NS & NS & NS \\
\hline MAP $\mathrm{mmHg}$ & $91 \pm 11$ & $87 \pm 12$ & $85 \pm 12$ & NS & $<0.05$ & NS \\
\hline $\mathrm{CO} L \cdot \min ^{-1}$ & $5.5 \pm 1.14$ & $4.7 \pm 0.98$ & $4.0 \pm 0.96$ & $<0.001$ & $<0.001$ & $<0.001$ \\
\hline $\mathrm{CO} \%^{\#}$ & $100 \pm 0.0$ & $84.4 \pm 6.5$ & $72.5 \pm 7.6$ & $<0.001$ & $<0.001$ & $<0.001$ \\
\hline $\mathrm{CI} \mathrm{L} \cdot \mathrm{min}^{-1} \cdot \mathrm{m}^{-2}$ & $3.23 \pm 0.7$ & $2.74 \pm 0.6$ & $2.33 \pm 0.56$ & $<0.001$ & $<0.001$ & $<0.001$ \\
\hline $\mathrm{SO}_{2} \%$ baseline & $92.6 \pm 1.9$ & $91.7 \pm 4.5$ & $93.4 \pm 4.5$ & NS & NS & NS \\
\hline $\mathrm{Do}_{2} \mathrm{~mL} \cdot \mathrm{min}^{-1}$ & $894 \pm 176$ & $740 \pm 150$ & $656 \pm 166$ & $<0.001$ & $<0.001$ & $<0.01$ \\
\hline $\mathrm{Do}_{2} / \mathrm{m}^{2} \mathrm{~mL} \cdot \mathrm{min}^{-1} \cdot \mathrm{m}^{-2}$ & $577 \pm 110$ & $462 \pm 93$ & $409 \pm 104$ & $<0.001$ & $<0.001$ & $<0.01$ \\
\hline
\end{tabular}

Data are presented as mean \pm SD, unless otherwise stated. SB: spontaneous breathing; Li: low-intensity; NPPV: noninvasive positive pressure ventilation; Hi: highintensity; SAP: systolic arterial pressure; DAP: diastolic arterial pressure; MAP: mean arterial pressure; fC: cardiac frequency; SV: stroke volume; CO: cardiac output. Cl: cardiac index; $\mathrm{SO}_{2}$ : oxygen saturation; $\mathrm{DO}_{2}$ : oxygen delivery capacity; $\mathrm{DO}_{2} / \mathrm{m}^{2}: \mathrm{DO}_{2}$ corrected for body surface area; NS: nonsignificant.

ventilation and, in COPD patients, LORX et al. [25] evaluated airway and tissue mechanics using a low-frequency oscillation technique and observed improved homogeneity of ventilation in peripheral airways during application of increasing PEEP. The higher $V \mathrm{~T}$ (and $V^{\prime} \mathrm{E}$ ) and greater airway pressure achieved with Hi-NPPV are probably responsible for the greater reversal of hypoventilation than with Li-NPPV, despite the greater air leaks associated with the higher inspiratory pressures.

Dyspnoea score was significantly reduced compared with SB, similarly with both modes of NPPV. Indeed, the presence of IEs, an index of patient/ventilator asynchrony, was also similar and very low with both settings. However, few of our patients (i.e. three out of 15) could not tolerate an inspiratory pressure $>25 \mathrm{cmH}_{2} \mathrm{O}$, so that we had to stop our stepwise increases at that level.

In contrast WINDISCH et al. [6] have shown that Hi-NPPV may be even better tolerated on a long-term basis, but the experience from our study suggests that the pressures applied should be individually and carefully titrated based on the patient's compliance and may need to be gradually increased over a longer period of time. Thus, no "fixed recipes" should be implemented.

A chief aim of Hi-NPPV, at least according to the philosophy of the proponents of this technique, is to achieve total control of the patient's spontaneous respiratory activity, but this has never been assessed. In our study, we have shown a dramatic reduction of PTPdi during Hi-NPPV by almost $90 \%$ from SB and 70\% from Li-NPPV, and nine out of 15 patients achieved nearly a complete resting of the diaphragm. The mechanisms by which such a decrease was mediated were related not only to the higher inspiratory support, but also to the decreased duty cycle and higher inspiratory flow observed with HiNPPV. Decreasing the patient's inspiratory time and increasing the inspiratory flow rate have previously been shown to reduce the effort of the diaphragm in COPD patients [26]. In view of this, it may be surprising that the reduction in respiratory rate from baseline that we observed during LiNPPV was relatively small compared with some other physiological studies [3]. However, it should be noted that in the latter physiological study, patients were experienced users already enrolled in a home mechanical ventilation programme, whereas our patients were naïve users.

We observed significant differences in cardiovascular performance between the various settings. As expected, both NPPV settings increased intrapleural and intrathoracic pressure and lung volume compared with $\mathrm{SB}$, and these independently influence right atrial filling (or pre-load) and impedance to right ventricular emptying (or afterload), which are the key determinants of cardiovascular performance. SB or partially assisted modes of ventilation (i.e. Li-NPPV) maintain negative pleural and intrathoracic pressure, which is transmitted to the right atrium. In contrast, controlled mechanical ventilation (i.e. Hi-NPPV in most cases) leads to a positive swing in $P$ pl during inspiration and, therefore, a higher right atrial pressure, which leads to decreased venous return and, consequently, a decreased right atrial preload. Moreover, the elevated lung volume during Hi-NPPV may have increased pulmonary vascular resistance $[8,9]$.

Our noninvasively obtained haemodynamic findings are consistent with previous observations made by MARANGONI et al. [27] and AmBrosino et al. [28]. In both of these studies, cardiac output was reduced during NPPV, especially when PEEP was also applied. Notably, these studies did not evaluate the cardiovascular effects of higher inspiratory positive airway pressure values, as utilised by us during Hi-NPPV. It is also important to note that, lacking indices of organ perfusion, the clinical consequences of the reduction in cardiac output that we observed are unknown and not necessarily adverse. Heart rate did not change and the decreases in MAP are of questionable clinical significance. In fact, it is conceivable that at least part of the reduction in $\mathrm{CO}$ reflects the lower metabolic demand that would be expected as respiratory muscles undergo complete rest. 
In conclusion, we have shown that Hi-NPPV in stable COPD patients is more effective than Li-NPPV at acutely improving gas exchange and reducing the patient's respiratory effort. Since it acts in most instances as a true controlled ventilation, it induces a positive pleural swing during inspiration, lowering $\mathrm{CO}$ and other indices of cardiac performance. The clinical significance of this effect needs further evaluation, especially in patients with pre-existing cardiovascular disease. Also, our observations are relevant only to acute physiological effects of Hi-NPPV and the long-term effects on sleep architecture, respiratory mechanics, gas exchange and cardiac performance require further study.

\section{SUPPORT STATEMENT}

We acknowledge the support of the Hungarian Pulmonological Foundation, the European Respiratory Society (ERS) and the Italian Interdisciplinary Association for Research in Lung Disease (AIMAR) (joint ERS/AIMAR Fellowship number 1392).

\section{STATEMENT OF INTEREST}

Statements of interest for N. Hill and S. Nava can be found at www.erj. ersjournals.com/site/misc/statements.xhtml

\section{REFERENCES}

1 Kolodziej MA, Jensen L, Rowe B, et al. Systematic review of noninvasive positive pressure ventilation in severe stable COPD. Eur Respir J 2007; 30: 293-306.

2 Schönhofer B. Non-invasive positive pressure ventilation in patients with stable hypercapnic COPD: light at the end of the tunnel? Thorax 2010; 65: 765-767.

3 Vitacca M, Nava S, Confalonieri M, et al. The appropriate setting of noninvasive pressure support ventilation in stable COPD patients. Chest 2000; 118: 1286-1293.

4 Appendini L. About the relevance of dynamic intrinsic PEEP (PEEPi,dyn) measurement. Intensive Care Med 1999; 25: 252-254.

5 Windisch W, Kostic S, Dreher M, et al. Outcome of patients with stable COPD receiving controlled noninvasive positive pressure ventilation aimed at a maximal reduction of $\mathrm{Pa}_{\mathrm{a}} \mathrm{CO}_{2}$. Chest 2005; 128: 657-662.

6 Windisch $\mathrm{W}$, Haenel $\mathrm{M}$, Storre $\mathrm{JH}$, et al. High-intensity noninvasive positive pressure ventilation for stable hypercapnic COPD. Int J Med Sci 2009; 6: 72-76.

7 Dreher M, Storre JH, Schmoor C, et al. High-intensity versus lowintensity non-invasive ventilation in patients with stable hypercapnic COPD: a randomised crossover trial. Thorax 2010; 65: 303-308.

8 Shekerdemian L, Bohn D. Cardiovascular effects of mechanical ventilation. Arch Dis Child 1999; 80: 475-480.

9 Steingrub JS, Tidswell M, Higgins TL. Hemodynamic consequences of heart-lung interactions. J Intensive Care Med 2003; 18: 92-99.

10 Thys $\mathrm{F}$, Liistro $\mathrm{G}$, Dozin $\mathrm{O}$, et al. Determinants of $\mathrm{FI}_{1} \mathrm{O}_{2}$ with oxygen supplementation during noninvasive two-level positive pressure ventilation. Eur Respir J 2002; 19: 653-657.
11 Tobin MJ. Monitoring respiratory mechanics in spontaneously breathing patients. In: Tobin MJ, ed. Principles and Practice of Intensive Care Monitoring. Columbus, McGraw-Hill, 1998; pp. 621-628.

12 Iotti GA, Braschi A. Misure della PEEPi [Measurement of PEEPi]. In: Iotti GA, Braschi A, eds. Misure di Meccanica Respiratoria Durante Ventilazione Artificiale [Measurements of Respiratory Mechanics During Artificial Ventilation]. Rhäzüns, Hamilton Medical AG, 2001; pp. 54-65.

13 Bogert LW, van Lieshout JJ. Non-invasive pulsatile arterial pressure and stroke volume changes from the human finger. Exp Physiol 2005; 90: 437-446.

14 Jansen JR, Schreuder JJ, Mulier JP, et al. A comparison of cardiac output derived from the arterial pressure wave against thermodilution in cardiac surgery patients. Br J Anaesth 2001; 87: 212-222.

$15 \mathrm{Lu} \mathrm{Z}$, Mukkamala R. Continuous cardiac output monitoring in humans by invasive and noninvasive peripheral blood pressure waveform analysis. J Appl Physiol 2006; 101: 598-608.

16 Grizzle JE. The two-period change-over design and its use in clinical trials. Biometrics 1965; 21: 467-480.

17 Hills M, Armitage P. The two-period cross-over clinical trial. Br J Clin Pharmacol 1979; 8: 7-20.

18 Windisch W, Vogel M, Sorichter S, et al. Normocapnia during nIPPV in chronic hypercapnic COPD reduces subsequent spontaneous $\mathrm{Pa}_{\mathrm{a}} \mathrm{CO}_{2}$. Respir Med 2002; 96: 572-579.

19 Aida A, Miyamoto K, Nishimura M, et al. Prognostic value of hypercapnia in patients with chronic respiratory failure during long-term oxygen therapy. Am J Respir Crit Care Med 1998; 158: 188-193.

20 Levine S, Nguyen T, Taylor N, et al. Rapid disuse atrophy of diaphragm fibers in mechanically ventilated humans. N Eng J Med 2008; 358: 1327-1335.

21 Levine S, Nguyen T, Kaiser LR. Human diaphragm remodelling associated with COPD: clinical implications. Am J Respir Crit Care Med 2003; 168: 706-713.

22 Sassoon $\mathrm{CH}$, Zhu E, Caiozzo VJ. Assist-control mechanical ventilation attenuates ventilator-induced diaphragmatic dysfunction. Am J Respir Crit Care Med 2004; 170: 626-632.

23 Williams MH Jr. V/Q inhomogeneity causes increased physiologic dead space. Chest 1986; 89: 904.

24 Neumann P, Hedenstierna G. Ventilatory support by continous positive airway pressure breathing improves gas exchange as compared with partial ventilatory support with airway pressure release ventilation. Anest Analg 2001; 92: 950-958.

25 Lorx A, Szabó B, Hercsuth M, et al. Low-frequency assessment of airway and tissue mechanics in ventilated COPD patients. J Appl Physiol 2009; 107: 1884-1892.

26 Prinianakis G, Delmastro M, Carlucci A, et al. Effect of varying the pressurisation rate during noninvasive pressure support ventilation. Eur Respir J 2004; 23: 314-320.

27 Marangoni S, Vitacca M, Quadri A, et al. Non-invasive haemodynamic effects of two nasal positive pressure ventilation modalities in stable chronic obstructive lung disease patients. Respiration 1997; 64: 138-144.

28 Ambrosino N, Nava S, Torbicki A, et al. Haemodynamic effects of pressure support and PEEP ventilation by nasal route in patients with stable chronic obstructive disease. Thorax 1993; 48: 523-528. 